\title{
Area Selective Deposition of Metals from the Electrical Resistivity of the Substrate
}

\author{
Hama Nadhom, Robert Boyd, Polla Rouf, Daniel Lundin, and Henrik Pedersen*
}

Cite This: J. Phys. Chem. Lett. 2021, 12, 4130-4133

Read Online

ACCESS | LWll Metrics \& More

ABSTRACT: Area selective deposition (ASD) of films only on desired areas of the substrate opens for less complex fabrication of nanoscaled electronics. We show that a newly developed CVD method, where plasma electrons are used as the reducing agent in deposition of metallic thin films, is inherently area selective from the electrical resistivity of the substrate surface. When depositing iron with the new CVD method, no film is deposited on high-resistivity $\mathrm{SiO}_{2}$ surfaces whereas several hundred nanometers thick iron films are deposited on areas with low resistivity, obtained by adding a thin layer of silver on the $\mathrm{SiO}_{2}$ surface. On the basis of such a scheme, we show how to use the electric resistivity of the substrate surface as an extension of the ASD toolbox for metal-on-metal deposition.

Article Recommendations

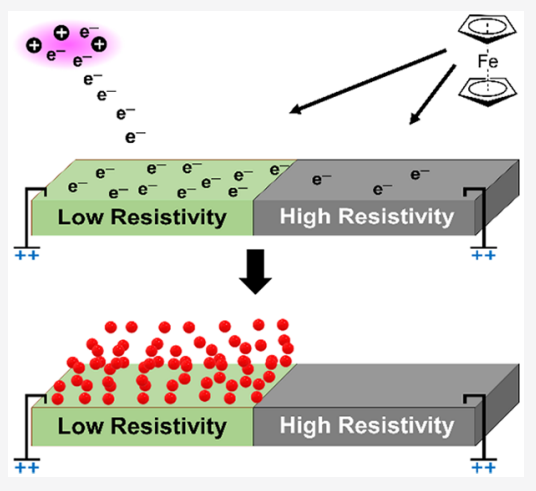

$\mathrm{M}$ iniaturization of electronic components has increased the demand for precise and improved thin film deposition methods. For example, deposition only on desired areas would avoid the need for patterning and etching steps and allow for bottom-up fabrication of nanoscaled structures. This has motivated research into area selective deposition (ASD) by chemical vapor deposition (CVD) techniques. ${ }^{1-3}$ The selectivity in ASD is usually achieved by changing the surface chemistry of the area where film growth is either desired or not desired to control the adsorption of precursor molecules to only specific areas on the substrate. Different methods have been reported to enable ASD. Self-assembled monolayers of organic molecules are often used to block areas of the surface where no film growth is desired. ${ }^{4}$ Film nucleation can also be inhibited on certain areas on the surface by surface passivation using ion implantation of fluorocarbons ${ }^{5}$ or by poisoning the surface by inhibitors such as fluorine, hydrogen, or ammonia. ${ }^{6,7}$ ASD can also be achieved by utilizing different film growth rate or nucleation rates on different materials on the substrate. ${ }^{8}$ This approach can be further enhanced by adding etching steps to the deposition process. 9

We recently reported a new CVD method for deposition of metallic films where the free electrons in a plasma are used as reducing agents. ${ }^{10}$ Because the method draws an electron current from the plasma to an electrically biased substrate, a conducting surface is needed to close the electric circuit allowing the electron current to flow from the plasma discharge to the bias power supply without any charge buildup. Therefore, metallic films could be deposited on electrically conducting silver substrates, while the deposition process was hampered on poorly conductive silicon and inactive on insulating silicon dioxide substrates. Here, we show how this inherent surface selectivity can be used to afford an area selective deposition of metallic thin films on only areas of a substrate surface that are electrically conducting.

Iron films were deposited from ferrocene, bis(cyclopentadienyl) $\mathrm{Fe}(\mathrm{II})\left(\mathrm{FeCp}_{2}\right)$, with plasma electrons as reducing agents on a $1 \times 2 \mathrm{~cm}^{2} \mathrm{Si}(100)$ substrate with a 300 $\mathrm{nm}$ thermally grown $\mathrm{SiO}_{2}$ layer, partially covered by a $40 \mathrm{~nm}$ thick layer of sputter-coated silver. The deposition system setup and the experimental procedures of our new CVD method are described elsewhere. ${ }^{10}$ Briefly, the depositions were performed in a vacuum chamber equipped with a hollow cathode plasma source located in the top lid of the vacuum chamber. Argon was used as working gas at a flow rate of 70 sccm through the titanium hollow cathode. The plasma discharge was maintained at $70 \mathrm{~W}$ in DC mode at a working gas pressure of $25 \mathrm{~Pa}$. $\mathrm{FeCp}_{2}$ was supplied by evaporation at 70 ${ }^{\circ} \mathrm{C}$, and the vapor was drawn into the deposition chamber by the chamber vacuum. The stainless-steel substrate holder $(65$ $\times 42 \times 1 \mathrm{~mm}^{3}$ ) was placed in the precursor stream, upstream from the plasma source to allow precursors to adsorb on the substrate without entering the plasma bulk to minimize plasma

Received: February 5, 2021

Accepted: April 21, 2021

Published: April 22, 2021 
chemical decomposition of the metal precursors. A DC bias voltage of $40 \mathrm{~V}$, connected to the steel sample holder, was used to attract the plasma electrons to the substrate. Drawing an electronic current resulted in a slight heating of the substrate holder, and a temperature of $40{ }^{\circ} \mathrm{C}$ was measured by a thermocouple spot-welded to the backside of the substrate holder. This was regarded as the deposition temperature as no other heating was used. The substrates were electrically connected to the substrate holder by using silver paint on both the silver-coated and the $\mathrm{SiO}_{2}$ sides of the substrate. The deposition time was $60 \mathrm{~s}$.

Cross-section scanning transmission electron microscopy (STEM) was used to determine the presence, thickness, and chemical structure of the deposited films. Prior to analysis, thin sections suitable for analysis by STEM were prepared by using the lift-out approach based on focused ion beam milling. ${ }^{11}$ All STEM analyses were performed by using a FEI Tecnai G2 TF $20 \mathrm{UT}$ instrument operated at $200 \mathrm{kV}$. Images were collected with an annular detector spanning the range 80-260 mrad. Top-view scanning electron microscopy (SEM) was done by using an LEO 1550 Gemini SEM instrument with an acceleration voltage of $3 \mathrm{kV}$. We determined the composition and the elemental mapping of the deposited films layers by energy dispersive X-ray spectroscopy (EDS) using the same SEM system with an acceleration voltage of $20 \mathrm{kV}$.

$\mathrm{X}$-ray photoelectron spectroscopy (XPS) was used to analyze the elemental composition and chemical bonding in the deposited films using monochromatic $\mathrm{Al} \mathrm{K} \alpha$ X-rays. A charge neutralizer filament was used to compensate for the charge buildup effect. The conditions used for survey scans were as follows: energy range $=0-1200 \mathrm{eV}$, pass energy $=160$ $\mathrm{eV}$, step size $=0.1 \mathrm{eV}$, and $\mathrm{X}$-ray spot size $=2 \mathrm{~mm}$ in diameter. A binding energy range of $20-40 \mathrm{eV}$ (depending on the examined peak) was used for high-resolution spectra with a pass energy of $20 \mathrm{eV}$. Argon $(0.5 \mathrm{keV})$ was used as the sputtering source. The $\mathrm{C} 1 \mathrm{~s}$ peak with a value of $285 \mathrm{eV}$ was used for calibration in all spectra. Gaussian-Laurentius (GL) functions and a Shirley background were used to fit the experimental XPS data.

Cross-section STEM analysis (Figure 1) shows that an $\sim 400$ $\mathrm{nm}$ thick film is deposited on the Ag-coated areas of the $\mathrm{SiO}_{2}$ (resistivity $\left.\rho_{\mathrm{Ag}, \text { bulk }}=1.59 \times 10^{-8} \Omega \cdot \mathrm{m}\right)^{12}($ Figure $1 \mathrm{a})$, while no (a)

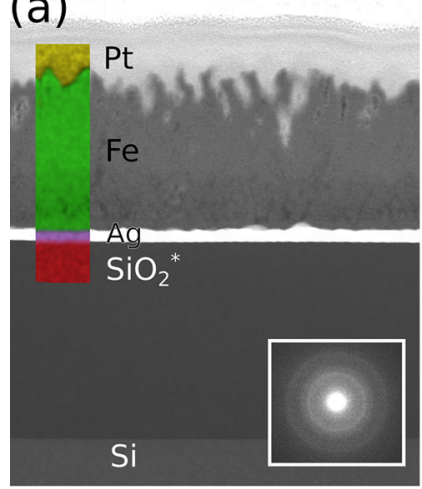

* - determined from Si signal

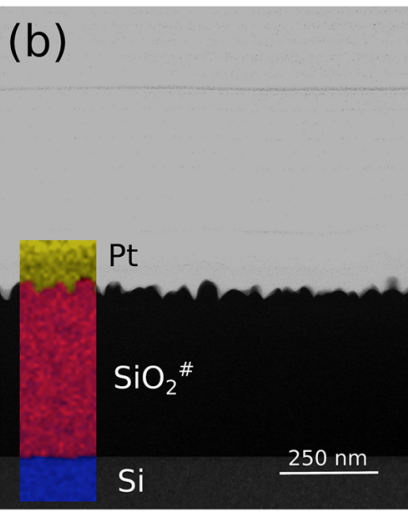

\# - determined from O signal
Figure 1. Cross-sectional scanning transmission electron micrographs on the substrate regions with (a) and without (b) Ag coating. Insets show the compositional maps, which were derived directly from the STEM-EDS data. SAED of the deposited films are given as insets. film can be seen on the bare $\mathrm{SiO}_{2}$ (resistivity $\rho_{\text {Silica }}=5 \times 10^{11}-$ $\left.10^{14} \Omega \cdot \mathrm{m}\right)^{12}$ (Figure $1 \mathrm{~b}$ ). The deposited Fe film is relatively rough, with height variations of $100 \mathrm{~nm}$ and porous; the film appears more dense near the Ag layer. Compositional mapping by STEM-EDS (insets in Figures $1 \mathrm{a}$ and $1 \mathrm{~b}$ ) reveals that the film deposited on Ag-coated area is Fe-rich. Further analysis of the EDS data shows that the film also has a high $\mathrm{O}$ content (composition $\mathrm{FeO}_{1.3}$ ) with trace amounts of $\mathrm{Ti}$ and $\mathrm{C}$. The presence of $\mathrm{Ti}$ is most likely due to sputtering of the titanium hollow cathode, and the presence of $\mathrm{C}$ is in part due to contamination during preparation and analysis. This indicates that the analyzed films have a high concentration of iron oxide due to the porous nature of the film (Figure 1), a significant portion of which could have been formed when the newly revealed $\mathrm{Fe}$ was exposed to air. The selected area electron diffraction of the iron film shows no diffraction spots, and HRTEM analysis of the film could not resolve any diffraction fringes (data not shown), both of which indicate that the film is amorphous when analyzed. The TEM analysis of the substrate areas not coated by Ag shows no film growth, and no iron could be detected by EDS.

From the TEM analysis it is seen that both the deposited iron and the uncoated silicon oxide substrate material have a very rough morphology with height variations of $50 \mathrm{~nm}$. As we cannot deposit an oxidation-blocking cap layer after the metal deposition in our deposition system, we deposit thicker $\mathrm{Fe}$ films to avoid complete oxidation of the very oxyphilic Fe film. This meant that we used much longer processing times than needed for any relevant application in nanometer-scaled electronic applications where typical film thicknesses of only a few tens of nanometers are needed. From Figure 1 it is seen that the first $\sim 100 \mathrm{~nm}$ close to the Ag interface is significantly denser as compared to the top surface. This region is also more than a relevant film thickness for electronics applications. The longer deposition meant that whatever mechanism causing the increased surface roughness on the $\mathrm{SiO}_{2}$ was exaggerated. Thus, deposition of thinner Fe films is expected to significantly reduce the surface roughness on the $\mathrm{SiO}_{2}$. We speculate that the roughening mechanism is somewhat similar to preferential sputtering of insulating layers in asymmetric bipolar DCsputtering discharges, as described by Sellers. ${ }^{13}$ The insulating $\mathrm{SiO}_{2}$ forms a parasitic capacitor, which leads to the plasmafacing surface of the insulator to be charged toward $-40 \mathrm{~V}$ when applying $+40 \mathrm{~V}$ to the sample holder. This opens for positive ion acceleration toward the $\mathrm{SiO}_{2}$ surface and thereby etching of the top surface. There is also the possibility that we build up voltage on the compound which could cause a breakdown of these parasitic capacitors, ${ }^{14}$ also resulting in increased surface roughness.

Top view SEM with EDS elemental mapping of the interface between the Ag-coated and bare $\mathrm{SiO}_{2}$ surfaces (Figure 2) further show the area selectivity of the deposition process with Fe detected only on the Ag-coated area.

High-resolution XPS of the Fe spectral region recorded from the $\mathrm{Si} / \mathrm{SiO}_{2}$ substrate areas with and without $\mathrm{Ag}$ coating (Figure 3) shows that the films deposited on the Ag-coated areas consist of iron, confirming the EDS analysis (Figures 1 and 2). The XPS analysis shows that the films deposited on the Ag-coated areas are mixed iron oxides in the as-deposited, untreated samples. The $\mathrm{Fe} 2 \mathrm{p}$ region (Figure $3 \mathrm{a}$ ) shows peaks at $709.5-711.5 \mathrm{eV}$, corresponding to $\mathrm{Fe}-\mathrm{O} .^{15}$ It should be noted that these samples were subjected to air prior to being loaded into the XPS chamber, and given the oxyphilic nature of 

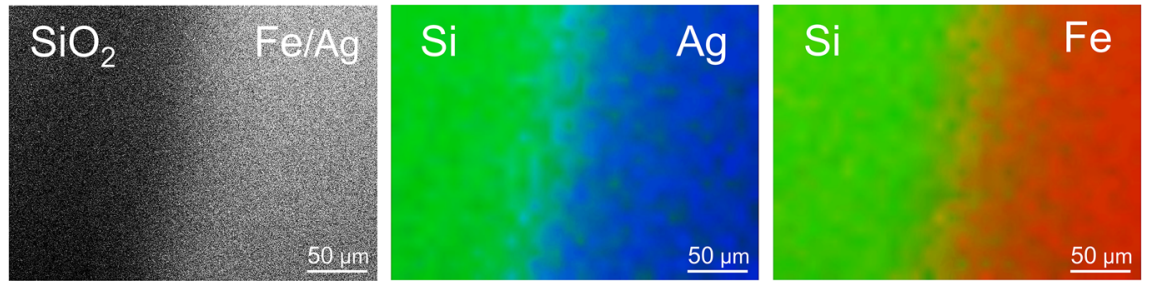

Figure 2. Top-view scanning electron micrographs on the interface between the Ag-coated and bare $\mathrm{SiO}_{2}$ surface regions. The elemental mapping by energy dispersive X-ray spectroscopy shows that the $\mathrm{Fe}$ is deposited only on the Ag-coated surface region.

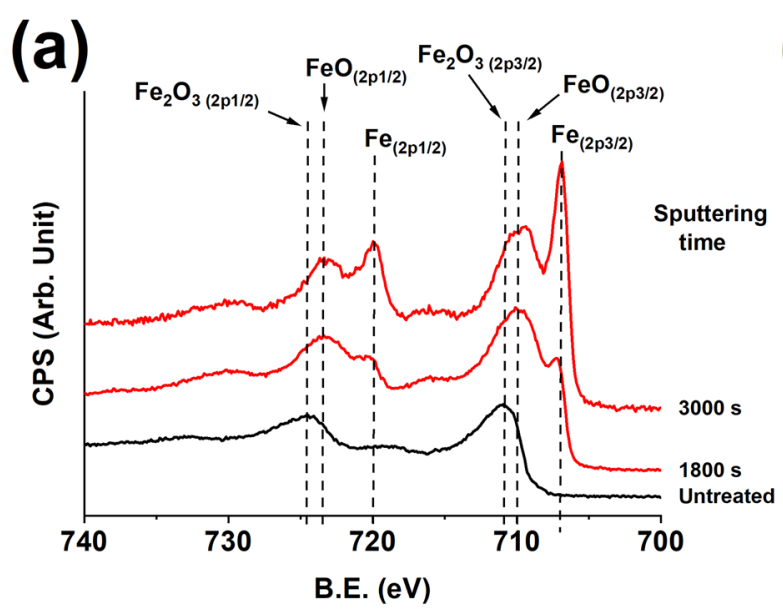

(b)

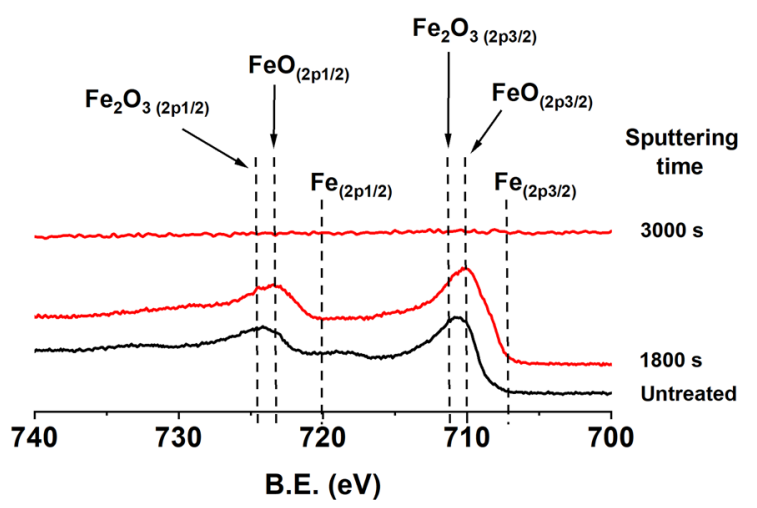

Figure 3. High-resolution XPS spectra, showing the iron spectral region of deposited films on (a) the substrate regions with $\mathrm{Ag}$-coated $\mathrm{SiO}_{2}$ and (b) without Ag-coated $\mathrm{SiO}_{2}$.

iron, surface oxidation is expected. Film deposition was also done in medium vacuum, meaning that low levels of oxygen exposure are to be expected during the deposition. ${ }^{16}$ The films where therefore sputter cleaned in the XPS chamber. After $1800 \mathrm{~s}$ sputtering, shoulder peaks at 706.9 and $720.1 \mathrm{eV}$ $(\Delta 13.2 \mathrm{eV})$ corresponding to zerovalent $\mathrm{Fe} 2 \mathrm{p}_{3 / 2}$ and $\mathrm{Fe}$ $2 \mathrm{p}_{1 / 2}$, ${ }^{15,17}$ respectively, can be seen (Figure $3 \mathrm{a}$ ). After further sputtering to a total sputter time of $3000 \mathrm{~s}$ these peaks dominate the spectra. The composition analysis by XPS of sputtered clean films deposited on the Ag-coated $\mathrm{SiO}_{2}$ shows 40 at. $\% \mathrm{Fe}, 19.5$ at. $\% \mathrm{C}, 35$ at. $\% \mathrm{O}, 2.6$ at. $\% \mathrm{~N}$, and 2.9 at. \% $\mathrm{Ti}$. In contrast, XPS analysis of the $\mathrm{Si} / \mathrm{SiO}_{2}$ substrate areas not coated by Ag shows very similar, albeit weaker, peaks, ascribed to iron oxides, in the as-deposited samples (Figure $3 \mathrm{~b}$ ). As these films were sputter cleaned for $1800 \mathrm{~s}$, no change in peak position is observed, and the peaks in the iron spectral region vanish after $3000 \mathrm{~s}$ sputtering on the $\mathrm{SiO}_{2}$ substrate, indicating a very thin iron oxide which could not be detected in the STEM analysis (Figure 1b). This shows that the amount of $\mathrm{Fe}$ deposited on the $\mathrm{SiO}_{2}$ substrate is very low compare to films deposited on the Ag-coated part of the substrate.

Our experimental results show that $\mathrm{Fe}$ has been selectively deposited on $\mathrm{Ag}$, adding to the previous literature on ASD of $\mathrm{Fe}$ on metals. ${ }^{18}$ Our results also suggest that the electrical resistivity of the surface determines the ability to deposit metallic films by this CVD method and that the CVD method is inherently area selective from the surface electrical resistivity. This inherent area selectivity of the new CVD process, where plasma electrons are used as reducing agents, does not depend on any thermodynamic or kinetic factors, as in other inherent ASD processes. ${ }^{19}$ Instead, creating a low-resistivity path for the electron flux from the plasma discharge to the substrate bias supply via the substrate surface is the prerequisite for the deposition chemistry in this new CVD process. We believe that this opens for exciting new possibilities for metal deposition selectively on metals.

\section{AUTHOR INFORMATION}

\section{Corresponding Author}

Henrik Pedersen - Department of Physics, Chemistry and Biology, Linköping University, SE-58183 Linköping, Sweden; (1) orcid.org/0000-0002-7171-5383;

Email: henrik.pedersen@liu.se

\section{Authors}

Hama Nadhom - Department of Physics, Chemistry and Biology, Linköping University, SE-58183 Linköping, Sweden

Robert Boyd - Department of Physics, Chemistry and Biology, Linköping University, SE-58183 Linköping, Sweden; (1) orcid.org/0000-0002-6602-7981

Polla Rouf - Department of Physics, Chemistry and Biology, Linköping University, SE-58183 Linköping, Sweden; () orcid.org/0000-0002-1452-4548

Daniel Lundin - Department of Physics, Chemistry and Biology, Linköping University, SE-58183 Linköping, Sweden

Complete contact information is available at:

https://pubs.acs.org/10.1021/acs.jpclett.1c00415

\section{Notes}

The authors declare the following competing financial interest(s): Henrik Pedersen and Hama Nadhom have filed a patent on the described CVD method. 


\section{ACKNOWLEDGMENTS}

Michal Zanaska is acknowledged for assistance in sputtering the silver coating on the substrates. Financial support from the Swedish Research Council (VR) under Contracts 2015-03803 and 2019-05055, the Swedish Foundation for Strategic Research (SSF) under Contract SSF-RMA 15-0018, and the Lam Research Corporation is gratefully acknowledged.

\section{REFERENCES}

(1) Carlsson, J.-O. Selective Vapor-Phase Deposition on Patterned Substrates. Crit. Rev. Solid State Mater. Sci. 1990, 16, 161-212.

(2) Mackus, A. J. M.; Merkx, M. J. M.; Kessels, W. M. M. From the Bottom-Up: Toward Area-Selective Atomic Layer Deposition with High Selectivity. Chem. Mater. 2019, 31, 2-12.

(3) Parsons, G. N.; Clark, R. D. Area-Selective Deposition: Fundamentals, Applications, and Future Outlook. Chem. Mater. 2020, 32, 4920-4953.

(4) Hashemi, F. S. M.; Birchansky, B. R.; Bent, S. F. Selective Deposition of Dielectrics: Limits and Advantages of Alkanethiol Blocking Agents on Metal-Dielectric Patterns. ACS Appl. Mater. Interfaces 2016, 8, 33264-33272.

(5) Kim, W.-H.; Hashemi, F. S. M.; Mackus, A. J. M.; Singh, J.; Kim, Y.; Bobb-Semple, D.; Fan, Y.; Kaufman-Osborn, T.; Godet, L.; Bent, S. F. A Process for Topographically Selective Deposition on 3D Nanostructures by Ion Implantation. ACS Nano 2016, 10, 44514458.

(6) Kalanyan, B.; Lemaire, P. C.; Atanasov, S. E.; Ritz, M. J.; Parsons, G. N. Using Hydrogen To Expand the Inherent Substrate Selectivity Window During Tungsten Atomic Layer Deposition. Chem. Mater. 2016, 28, 117-126.

(7) Mohimi, E.; Zhang, Z. V.; Liu, S.; Mallek, J. L.; Girolami, G. S.; Abelson, J. R. Area Selective CVD of Metallic Films from Molybdenum, Iron, and Ruthenium Carbonyl Precursors: Use of Ammonia to Inhibit Nucleation on Oxide Surfaces. J. Vac. Sci. Technol., A 2018, 36, 041507.

(8) Kerrigan, M. M.; Klesko, J. P.; Rupich, S. M.; Dezelah, C. L.; Kanjolia, R. K.; Chabal, Y. J.; Winter, C. H. Substrate Selectivity in the Low Temperature Atomic Layer Deposition of Cobalt Metal Films from Bis(1,4-di-tert-butyl-1,3-diazadienyl)Cobalt and Formic Acid. J. Chem. Phys. 2017, 146, 052813.

(9) Vos, M. F. J.; Chopra, S. N.; Verheijen, M. A.; Ekerdt, J. G.; Agarwal, S.; Kessels, W. M. M.; Mackus, A. J. M. Area-Selective Deposition of Ruthenium by Combining Atomic Layer Deposition and Selective Etching. Chem. Mater. 2019, 31, 3878-3882.

(10) Nadhom, H.; Lundin, D.; Rouf, P.; Pedersen, H. Chemical Vapor Deposition of Metallic Films Using Plasma Electrons as Reducing Agents. J. Vac. Sci. Technol., A 2020, 38, 033402.

(11) Langford, R. M.; Petford-Long, A. K. Preparation of Transmission Electron Microscopy Cross-Section Specimens Using Focused Ion Beam Milling. J. Vac. Sci. Technol., A 2001, 19, 2186.

(12) CRC Handbook of Chemistry and Physics, 97th ed.; Haynes, W. M., Ed.; CRC Press: Boca Raton, FL, 2017.

(13) Sellers, J. Asymmetric Bipolar Pulsed DC: The Enabling Technology for Reactive PVD. Surf. Coat. Technol. 1998, 98, 12451250.

(14) Schiller, S.; Goedicke, K.; Reschke, J.; Kirchhoff, V.; Schneider, S.; Milde, F. Pulsed Magnetron Sputter Technology. Surf. Coat. Technol. 1993, 61, 331-337.

(15) Sault, A. G. Quantitative Analysis of Auger Lineshapes of Oxidized Iron. Appl. Surf. Sci. 1994, 74, 249-262.

(16) Rayner, G. B.; O’Toole, N.; Shallenberger, J.; Johs, B. Ultrahigh Purity Conditions for Nitride Growth with Low Oxygen Content by Plasma-Enhanced Atomic Layer Deposition. J. Vac. Sci. Technol., A 2020, 38, 062408.

(17) Peng, D. L.; Sumiyama, K.; Oku, M.; Konno, T. J.; Wagatsuma, K.; Suzuki, K. X-Ray Diffraction and X-Ray Photoelectron Spectra of Fe-Cr-N Films Deposited by DC Reactive Sputtering. J. Mater. Sci. 1999, 34, 4623-4628.
(18) Low, Y. H.; Bain, M. F.; Bien, D. C. S.; Montgomery, J. H.; Armstrong, B. M.; Gamble, H. S. Selective Deposition of CVD Iron on Silicon Dioxide and Tungsten. Microelectron. Eng. 2006, 83, 22292233.

(19) Cao, K.; Cai, J.; Chen, R. Inherently Selective Atomic Layer Deposition and Applications. Chem. Mater. 2020, 32, 2195-2207. 